\title{
Creative Learning Methodology using Revised Bloom's Taxonomy
}

\author{
V Evelyn Brindha \\ Karunya Institute of Technology and Sciences, \\ Coimbatore, Tamilnadu, India
}

\begin{abstract}
Education is not the filling of a pail, but the lighting of a fire. In its ultimate form, education should be socially progressive. In an engineering college we teach the next generation of scientists, engineers and medical researchers who will improve our quality of life: they will learn more about the world, fabricate better and safer modes of transport, treat diseases and surmount scientific boundaries. Acquiring practical skills in addition to experimental theory is crucial to ensuring student learning capability and employability. Particularly, the industries emphasis on developing practical skills to produce graduates who are "workplace ready". This work emphasis on two areas such as Student centered learning pedagogy and formative assessment as an apt tool to enhance practical learning and employability skills to engineering graduates. The student centered learning pedagogy model proposed in this work and followed in our institute not only profound subject knowledge it also fosters the creative ability of the students in problem solving situations. It is widely recognized that formative assessment is an important tool to access on student learning, affecting engagement, motivation and effort. There is considerable scope for improvement in undergraduate practical assessment where concerns such as over assessment, authenticity and graduate skills are acknowledged. This work aims to develop a step by step process on the implementation of the student centered pedagogy and a digital approach for applying the principles of good assessment and instant feedback to assessment obtained to students. The work seeks to utilize the potential of digital technologies to facilitate peer and self-assessment, promoting greater self-regulation among students.
\end{abstract}

\section{Introduction}

A new way of teaching and learning need has to originate that critically engage student in rich learning environments. As mature and more diverse types of students enter higher education, it is vital that the traditional role of the educator as one who offers content knowledge has to be broadened so that teaching is aimed at developing students' capacity to create their own understandings and insights through participation, negotiation and dialogue. According to Bertrand (2003, p. 310), as a person matures, his self-concept moves from one of being a dependent personality toward one of being a self-directed human being; he accumulates a growing reservoir of experience that becomes an increasing resource for learning; his readiness to learn becomes oriented increasingly to the developmental tasks of his social roles; his time perspective changes from one of postponed application of knowledge to immediacy of application, and accordingly his orientation toward learning shifts from one of subject-centeredness to one of problem centeredness.

\section{Creative Learning Methodology}

This work discusses on Creative Learning Methodology (CLM) using Revised Blooms Taxonomy and Formative Assessment with a Digital approach. Teaching for understanding is a thought that reveals teachers as guides, mentors, and facilitators of student learning. This work, which provides tangible illustrations of what teaching for understanding necessitates, is divided into five major stages.

\subsection{Stage 1: Micro planning}

Productivity is never an accident. It is always the result of a commitment to excellence, intelligent planning, and focused effort. The term micro comes from the Greek mikros meaning "small, little". In the paper, micro planning refers to planning one specific lesson based on one target. It involves choosing a topic and constructing a full lesson to harmonize it. A typical lesson plan involves a warmup activity such as evocation, which introduces the topic, followed by an explanation/lesson of the point to be covered. Finally, teachers should plan a brief wrap-up activity that brings the lesson to a close. 
Lesson planning ensures that you'll be prepared for every class and that you'll have a variety of activities on hand for whatever situation may arise. A sample micro planning for a class of one hour duration is shown in Figure 1. In the figure SO and FA means Specific Objective and Formative assessment respectively.

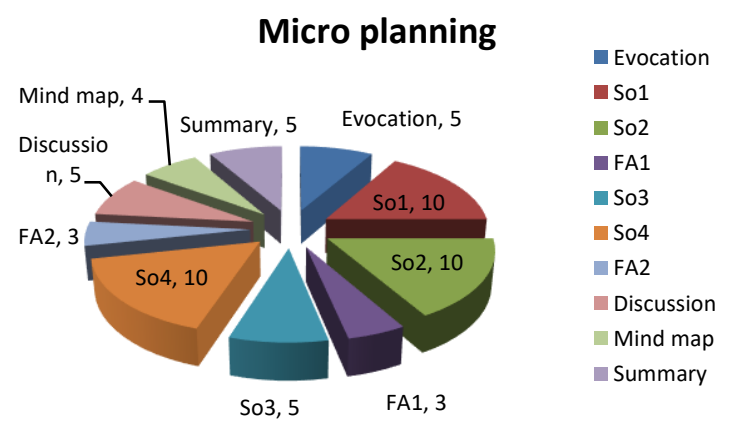

Figure 1.Microplanning for a one hour class.

\subsection{Stage 2: Evocation to the topic}

If the taste of a particular candy bar suddenly whisks us back to an earlier time in our life? That's an evocation, the summoning, usually unconscious, of a memory or emotional state caused by a particular stimulus. This process of evocation is done in every class by using an ICT tool as an appropriate tool. The various means of doing this evocation are

- Projecting a history and evolution of the topic

- Projecting the future advancements of the topic

- Projecting an application related to the topic and so on

Evocation need not be restricted to always making a presentation it can be a activity involving student's such as a case study discussion or a role play activity by the students to introduce a topic for the rest of the students in the class.

\subsection{Stage 3: Objective Oriented Learning}

Basic purpose of teaching is to enable learning. Objective based teaching is capable to bring transformation where student change from being passive recipients to knowledge to becoming active participant of the knowledge imbibing process. The most effective teaching is that which results in the most effective learning. Every class starts by stating the General objective and a few Specific objectives for the topic to be taught. These general and specific objectives should be in par with the revised bloom's taxonomy. Objectives are the prior specification of what teachers intend to teach and what is hoped that the learners will learn. All the specific objectives apart from being mapped with Science, Technology, Engineering or Mathematics (STEM) they are also mapped with activities for clear understanding purpose. Activities involving students are included where ever possible to provide room for broadening the base in better understanding of the topic. A well structured lesson plan is prepared for every class and it is well in advance uploaded and shared in Google drive with all the students in the class. Students can come for the class after glancing at the objectives for that particular hour. By doing this there are various upshots. Students can have access to the lesson plans by anyone at anytime and from anywhere. Defining the intended outcomes or the objectives has the following benefits such as choosing teaching/learning activities likely to lead to attaining the objectives, assessing students' learning outcomes to see how well they match what was intended and arriving at a final grade. The objectives based teaching has thick ingredients for bridging gap between professional and liberal education improving employability of students, Promoting students' thinking skill, inculcating clarity of thought and expression as well as nurturing team work. A sample general objective, specific objective and mapping of the objectives with Revised Bloom's taxonomy are shown below.

2.3.1. General Objective. Students will be able to understand the truth table and Boolean expression of 7 different logic gates and will be able to apply logic gate to draw logic diagrams for any combinational circuit.

2.3.2. Specific Objectives. Students will be able to:

1. Interpret the doping of impurities in semiconductors used to design logic gates. (S, E, M)

2. Construct the AND, OR and NOT gate using the 2 Universal gates. (E, M)

3. Compare the logic function of XOR and XNOR gate with one application each. (E, T, M)

4. Derive the logic diagram for a given application using logic gates. (E, T)

5. Demonstrate the concept of semiconductor and doping with an experiment and an animation video. (Activity) (S, E)

Table 1. Mapping of specific objectives using revised Bloom's Taxonomy

\begin{tabular}{|c|c|c|c|c|c|c|}
\hline \multirow{2}{*}{$\begin{array}{c}\text { Knowledge } \\
\text { Dimension }\end{array}$} & \multicolumn{5}{|c|}{ The Cognitive Process Dimension } \\
\cline { 2 - 7 } & Remembe & Understand & Apply & Analyse & Evaluate & Create \\
\hline Factual & & & & & & \\
\hline Conceptual & & 1 & & 3 & & \\
\hline Procedural & & & 2 & & & 4 \\
\hline
\end{tabular}




\begin{tabular}{|c|c|c|c|c|c|c|}
\hline $\begin{array}{c}\text { Meta } \\
\text { Cognitive }\end{array}$ & & 5 & & & & \\
\hline
\end{tabular}

The five specific objectives given above are mapped in the Revised Bloom's taxonomy table as shown in Table 1. The Knowledge dimension cut across subject matter lines. The new Knowledge dimension, however, contains four instead of three main categories. Three of them include the substance of the subcategories of Knowledge in the original framework. But they were reorganized to use the terminology, and to recognize the distinctions of cognitive psychology that developed since the original framework was devised. A fourth, and new category, Metacognitive Knowledge, provides a distinction that was not widely recognized at the time the original scheme was developed. Metacognitive Knowledge involves knowledge about cognition in general as well as awareness of and knowledge about one's own cognition according to Pintrich [1]. It is of increasing significance as researchers continue to demonstrate the importance of students being made aware of their metacognitive activity, and then using this knowledge to appropriately adapt the ways in which they think and operate. The four categories are shown in Table 1. According to Anderson [2], in the cognitive process domain when the objective of the instruction is to promote retention of the presented material in much the same form in which it was taught, the relevant process category is Remember. When the goal of instruction is to promote transfer, the focus shift to the other five cognitive process domain understand through create. Apply involves using procedures to perform exercises or solve problems and is closely linked with procedural knowledge. Analyse involves breaking material into its constituent parts and determining how the parts are related to each other and to an overall structure. Evaluate is defined as making judgments based on criteria and standards. The criteria most often used are quality, effectiveness, efficiency, and consistency. Create involve putting elements together to form a coherent or functional whole: that is, reorganizing the elements into a new pattern or structure.

\subsection{Stage 4: STEM in education}

STEM is the acronym for Science, Technology, Engineering, and Mathematics, and embraces a vast collection of subjects that fall into each of those terms. According to James [3], Breiner [4] and Borrego [5], and substantiated by the multitude of disciplines, it's lucid that STEM impinges on virtually every component of our daily lives.

Today's students are tomorrow's leaders. Employments in STEM-related careers are some of the fastest mounting and preeminent paid of the 21 st century, and they often have the greatest prospective for job growth. As students strives to keep up with the current and projected demand for STEM output, it is imperative that our country remains competitive in fields of science, technology, medicine, and all of the other STEM fields. The best way to make certain future success and longevity is to make certain that students are well versed in these subjects. Building a solid STEM underpinning through a well-rounded curriculum is the best way to ensure that students are exposed to math, science, and technology all through their educational career. In this regard, the objectives taught in the class not only embrace revised Bloom's Taxonomy but also fully integrates teaching the STEM concepts for the topic educated for the day.

\subsection{Stage 5: Formative assessment}

Formative assessment is the diagnostic use of assessment to provide feedback to teachers and students over the course of instruction. According to Boston [6], Yorke [7] and Harlen [8] the goal of formative assessment is to gain an understanding of what students know and dont know in order to make responsive changes in teaching and learning, techniques such as teacher observation and classroom discussion have an important place alongside analysis of tests and homework. Formative assessment refers to a broad range of methods that teachers use to conduct in-process evaluations of student comprehension, learning needs, and academic progress during a lesson, unit, or course. This is a shift in the classic educational epitome. As stated by Wiliam [9] formative assessment allows students to concentrate their hard work on specific areas and hence develop overall performance. This formative assessment is done in all the classes by using a very effective and easy tool called Flubaroo. As avowed by Dutton [10] Flubaroo is a free tool that helps you quickly grade multiplechoice or fill-in-blank assignments. It is a boon for teachers. More than just a grading tool, Flubaroo also computes average assignment score, computes average score per question, and flags low-scoring questions. It also shows you a grade distribution graph and gives you the option to email each student their grade, and an answer key. Lets you send individualized feedback to each student.

\section{Results and Discussion}

After conduction of formative assessments a survey was conducted among our students and the following were the results obtained in the survey. The four questions asked during the survey and the corresponding results obtained are discussed in this section. 


\subsection{Overall satisfaction}

As shown in Figure 2 after conducting a formative assessment test using the Flubaroo a survey was conducted among 3500 II, III and IV year students belonging to various engineering department. It is clearly evident from the pie chart that $59 \%$ of the students were satisfied and $11 \%$ were strongly satisfied in writing the formative assessment.

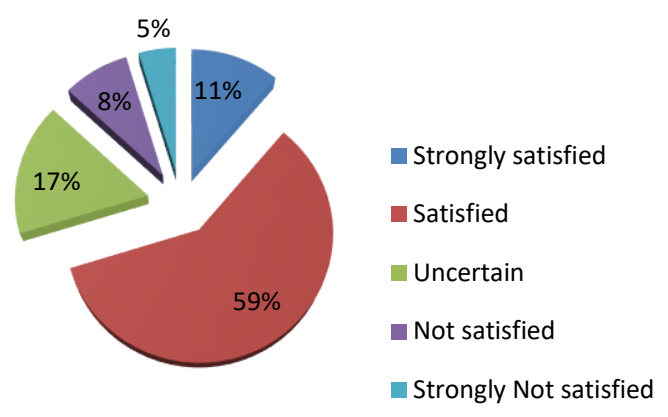

Figure 2.Overall satisfaction in writing FA

\subsection{Constructive for future reference}

As shown in Figure 3 the answer key will be mailed to individual students along with the overall score. These answers can be used for future reference and when it was surveyed $38.60 \%$ students strongly agreed and $47 \%$ students approved to the fact that it was useful for future reference.

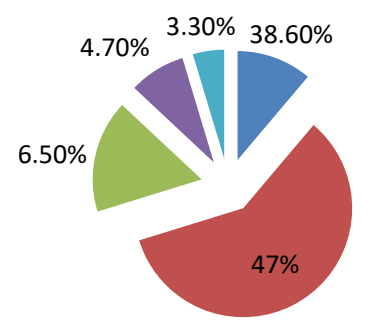

$$
\begin{aligned}
& \text { Strongly agree } \\
& \text { Agree } \\
& \text { Uncertain } \\
& \text { Disagree } \\
& \text { Strongly Disagree }
\end{aligned}
$$

Figure 3. Useful for future reference

\subsection{Instant and Comprehensive}

The conduction of formative assessment is easy, instant and all-inclusive not only for students but also for the faculty members as shown in Figure 4.

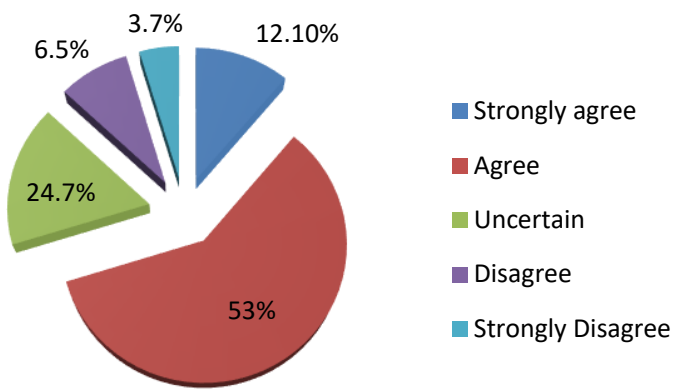

Figure 4. Instant and Comprehensive

\subsection{Students Experience}

From Figure 5 it is apparent that $27.90 \%$ students were strongly satisfied and $49.8 \%$ (almost 50\%) students were satisfied and felt in high spirits about the experience.

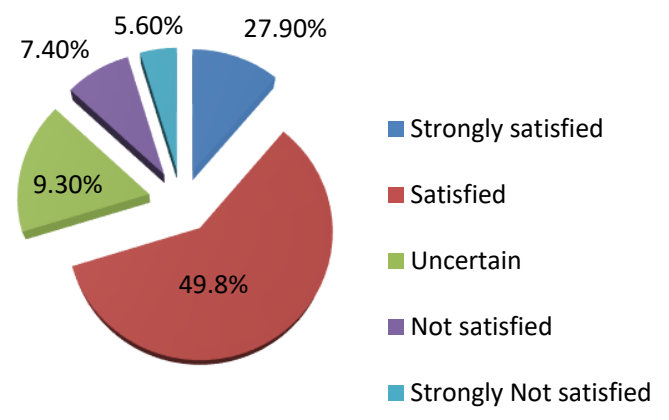

Figure 5. Experience of students

\section{Conclusion}

The primary goal of this paper is to examine how teaching and assessing can be broadened beyond and exclusive focus on the cognitive process. With an eye of improving practical learning and employability skills, there are two main advantages of using Revised Bloom's taxonomy. The first is it properly aligns objectives, activities and assessments. The second is to raise the learning targets in terms of cognitive complexity, type of knowledge (particularly metacognitive knowledge), or both. In addition to these general learning strategies, students can have knowledge of various metacognitive strategies and STEM concept that will be useful to them in planning, monitoring, and regulating their learning and thinking. 


\section{References}

[1] Pintrich, Paul R. "The role of metacognitive knowledge in learning, teaching, and assessing." Theory into practice 41.4 (2002): 219225.

[2] Anderson, Lorin W., David R. Krathwohl, and Benjamin Samuel Bloom. A taxonomy for learning, teaching, and assessing: A revision of Bloom's taxonomy of educational objectives. Allyn \& Bacon, 2001.

[3] Fairweather, James. "Linking evidence and promising practices in science, technology, engineering, and mathematics (STEM) undergraduate education." Board of Science Education, National Research Council, The National Academies, Washington, DC (2008).

[4] Breiner, Jonathan M., et al. "What is STEM? A discussion about conceptions of STEM in education and partnerships." School Science and Mathematics 112.1 (2012): 3-11.

[5] Borrego, Maura, and Charles Henderson. "Increasing the use of evidence-based teaching in STEM higher education: A comparison of eight change strategies." Journal of Engineering Education 103.2 (2014): 220-252.

[6] Boston, Carol. "The Concept of Formative Assessment. ERIC Digest." (2002).

[7] Yorke, Mantz. "Formative assessment in higher education: Moves towards theory and the enhancement of pedagogic practice." Higher education 45.4 (2003): 477-501.

[8] Harlen, Wynne, and Mary James. "Assessment and learning: differences and relationships between formative and summative assessment."Assessment in Education 4.3 (1997): 365-379.

[9] Wiliam, Dylan, and Paul Black. "Meanings and consequences: a basis for distinguishing formative and summative functions of assessment?." British Educational Research Journal 22.5 (1996): 537-548.

[10] Dutton, Lenny. "Google Forms: build free surveys." School Librarian 63.2 (2015): 83-84. 